\title{
Research On Wave Energy Generation Technology
}

\author{
Yang Yuxin ${ }^{1 *}$, Jin Zhemin ${ }^{2}$ \\ ${ }^{1}$ School energy and power engineering, Wuhan university of technology, Wuhan, Hubei, 430063, China \\ ${ }^{2}$ School energy and power engineering, Wuhan university of technology, Wuhan, Hubei, 430063, China
}

\begin{abstract}
With the increasingly serious environmental pollution and the intensified energy war, the allround development and utilization of marine energy will become an indispensable key link in China's implementation of the maritime power strategy. In recent years, with the support of the state, China's wave energy generation technology has made a key breakthrough.In order to protect the environment, save energy and reduce emissions, and promote the utilization of wave energy, this paper reviews the development history of application generation technology, summarizes its development from two aspects of optimization and application of wave energy conversion devices, and analyses the application examples of wave energy generation devices on ships. This paper summarizes the application trend of wave power generation devices on ships: wave power generation should be used as auxiliary and domestic electricity for ships and wave energy should be combined with other new energy sources. Wave energy application in marine power generation can effectively reduce emissions from ships, which is conducive to the sustainable development of human society.
\end{abstract}

\section{INTRODUCTION}

Affected by climate change and rising energy prices, the use of marine energy has received increasing attention internationally. Wave power generation and tidal current power generation are two types of energy development and utilization methods with relatively mature technologies and commercial development prospects in marine energy. Domestic and foreign scientific research institutes are continuously introducing different types of wave and tidal power generation devices.

Renewable energy has been established as one of the most prolific development areas in the twenty first century. The difficulties surrounding exploiting renewable energy resources are no longer related to developing novel technologies, but rather related to the transition and implementation of the renewable harvesting systems within the petrol based power grids around the world. Increase in demand for energy has stimulates socio-political pressure to explore sustainable and viable alternatives to fossil fuels. In particular, energy stored in ocean wind-generated waves is considered as an interesting alternative option to reduce the world energy dependence on fossil fuels. The world's energy demand is increasing, traditional fossil energy consumption is rapid, and the ecological environment is gradually deteriorating and seriously threatening the sustainable development of human society.

Solar energy, hydropower and wind energy are all being harvested by technologies which are witnessing a high rise in usage, and have been well established and optimized within industry manufacturers. Ocean energy conversion technology on the other hand, while it has a potentially higher efficiency and reduced complexity, is struggling to find its place in the renewable energy market.

\section{RESEARCH PROGRESS ON WAVE ENERGY CONVERSION TECHNOLOGY}

In the development and utilization of wave energy, according to the wave energy capture collection method, the wave energy utilization device can be classified into an oscillating water column type, a squat type, a pendulum type, a duck type, a wave type, and a point absorption type. The point absorption wave energy capture technology mainly uses the heave motion of the oscillating float under the action of wave force to collect the wave energy. Due to its high conversion efficiency, low construction difficulty, low investment cost and no influence on the wave direction, it is widely used. Pay attention to it. According to the number of oscillating floats, the point absorbing wave energy collecting device can be divided into three types: single floating body type, double floating body type and multi-floating type.

The early point-absorption WEC only had an oscillating float floating on the sea (single float, single degree of freedom) connected to the subsea fixture via a cable or column. For example, G-1T developed in Japan, L-10 developed by Oregon State University, USA, and AWS developed by Delft University of Technology in the Netherlands are all single floating type. Affected by ocean tides, the distance between the surface of the seawater and the seabed is changing at any time. The single floating body device needs to be connected with

\footnotetext{
* Corresponding author: 2554621237@qq.com
} 
the subsea fixture, so it is difficult to adapt to the change of tidal range and affect its promotion and application.

Double-floating WEC generally has two upper and lower floating bodies, one floating body floating on the water surface and the other floating body lying below the water surface. The floating surface of the water absorbs the wave energy, and the underwater floating body acts as a damping, providing a stable platform for the floating surface of the water surface. For example, the Wavebob device in Ireland consists of two coaxial symmetrical floats. The upper float is designed to match the incident wave frequency for resonance, while the lower float is designed to increase the inertia of the device and reduce pulsation. The device was tested on a $1 / 4$ scale sea trial in Galway Bay, Ireland. The US PowerBuoy device also has two upper and lower floating bodies. Floating on the sea surface is a dish-shaped floating body (oscillating float) with a horizontal damping plate at the end of the water. Its function is to increase the additional mass by using sea water body to increase the damping. The inertia of the plate takes up the wave energy by the relative motion between the dish-shaped float and the damper plate. PowerBuoy unit has been tested on a 40 $\mathrm{kW}$ prototype in the Gulf of San Tona, Spain.

In China, Ocean University of China conducted a simulation study on an oscillating floating-wave power generation system based on two-stroke hydraulic transmission. Southeast University focused on the design and analysis of a double-floating wave power plant based on a linear generator. The $120 \mathrm{~kW}$ double-floating floating wave hydraulic power unit studied by Shandong University and the $100 \mathrm{~kW}$ double-floating direct-drive wave energy device developed by the Guangzhou Institute of Energy Science of the Chinese Academy of Sciences also carried out sea trial tests. The two-degreeof-freedom system with two floating bodies can better overcome the tidal level change, is not affected by seawater depth and wave direction, and is easy to install and place. It has become the main development direction of point absorption WEC. However, the same as the single floating structure, only one oscillating floating body can only absorb the wave energy, so the size of the converted wave energy is limited.

\section{THE WAY WAVE ENERGY IS CONVERTED INTO ELECTRICITY}

\subsection{One conversion}

The primary conversion of wave energy mainly refers to the conversion of kinetic energy and potential energy of waves on the surface of the ocean into other forms of energy.

\subsubsection{Oscillating Water Column}

The oscillating water column wave power generation device is currently the most researched and used wave energy device. The basic principle is to use compressed air to drive the steam turbine generator set. According to the installation location, it can be divided into offshore, nearshore and docking. The oscillating water column type wave energy device has good reliability because there are no moving parts under water. The disadvantage is high cost and power generation efficiency of less than $30 \%$.

\subsubsection{Submerged Pressure Differential}

The submerged pressure differential pressure wave device works by using the wave crests and troughs of the waves to the pressure difference of the switching device. The Archimedes wave energy conversion device developed in the Netherlands uses the pressure difference to generate relative motion and drive the turbine or linear generator to generate electricity. The United States wave energy company developed a new type of pressure difference wave energy conversion device, using three special shape water floats, respectively, through the gears, racks to drive the generator to generate electricity.

Submerged pressure differential pressure wave device: The overall structure is underwater, which will not affect maritime shipping; it can avoid the damage of wave energy device caused by extreme weather. The disadvantage is that sealing and rust prevention are not guaranteed.

\subsubsection{Overtopping}

The diffuse wave energy device mainly collects the wave potential energy and converts it into electric energy by using a turbine. Denmark has designed two types of conical diffuse reflectors, "SSG," that use the over-wave effect to store and drive the turbine to generate electricity. Denmark's "Wave Dragon" diffuse reflector uses a dedicated waterway to store wave potential energy to a high level and convert it into electricity using a lowhead turbine. Sweden has developed a wave energy device for floating wave energy containers, which uses four floats to support the energy storage container with a power of 1.5 MW.

The diffuse power generation device is bulky, inefficient, has moving parts under water, and has low reliability.

\subsubsection{Oscillating Wave Surge Converter}

The oscillating wave surge converter works by using the elliptical motion characteristics of water particles. British Green Ocean Energy has designed an oyster wave energy conversion device that uses compressed water as a hydraulic oil to drive generators to generate electricity. Finland has designed an oscillating wave surge converter that uses a plunger pump to absorb the kinetic energy of the oscillating plate and transfer the kinetic energy to a closed hydraulic motor and generator combined hydraulic system. The oscillating rocking wave energy device has a simple structure and high efficiency. But only for shallow seas, hydraulic oil leaks can cause pollution. 


\subsection{Wave energy intermediate conversion}

Wave energy secondary conversion usually requires intermediate conversion links. The intermediate link processes energy such as mechanical energy to achieve stable, steady speed and accelerated energy transfer.

\subsubsection{Mechanical conversion}

Mechanical conversion is mainly composed of gears and other mechanisms. K. Rhinefrank designed a point absorbing wave energy device consisting of two floats and a Spar platform. It used a sealed drive shaft and gear mechanism to transmit wave sway and oscillating energy to the electromagnetic induction generator. Hadano $\mathrm{K}$ designed point absorber wave energy balance means by the rotation of the clutch and transmission of energy conversion mechanism growth.

Mechanical conversion is a traditional wave energy conversion method with mature technology; the disadvantage is low efficiency.

\subsubsection{Hydraulic conversion}

In 1980, McCabe proposed the hydraulic pump concept. The pump uses a two-wing pontoon to swing the hydraulic pump up and down at sea level, driving the hydraulic motor to drive the motor to obtain electrical energy. In 2005, OPD UK and the University of Edinburgh jointly developed the "Pelamis" conversion unit, which uses a cross-connect structure and a hydraulic cylinder to connect the float. The relative rotational energy of the float can be converted into hydraulic energy. In 2007, Wang Feng of Zhejiang University and other designers designed a new hydraulic power system that uses seawater to drive hydraulic systems with pressure changes in elastic vessels filled with hydraulic oil, achieving an efficiency of $63.8 \%$ in the 2,400 m deep sea.

The hydraulic energy can be stored for easy control and is suitable for energy conversion of wave energy transducing devices.

\subsubsection{Pneumatic conversion}

Pneumatic conversion typically uses air as a medium to convert air kinetic energy into turbine maneuver energy. Turbines are mainly divided into one-way rectifier turbines and two-way turbines. The one-way turbines are highly efficient and have a large structure. The two-way turbine is commonly used in Wells turbines, which does not require rectification and has high efficiency. The shortcoming angle of attack is too large and it is prone to stall.

\section{Conclusion}

Most wave power plants are mostly small-scale singlepoint devices, and the output power is still within kilowatts. Only by large-scale and integrated development, can wave energy use technology to achieve better commercial utilization. Therefore, a multipoint wave energy generating device having a plurality of oscillating floats at the same time, or a plurality of single-point absorbing wave energy devices being arranged in an array form a large-scale wave energy power plant, can make the installed capacity of the wave energy generating device reach Million watts, reducing power generation costs and improving power generation efficiency.

At present, wave energy utilization devices generally use the collected wave energy to be converted into electric energy through multi-stage conversion, and the application of wave energy to seawater desalination technology is relatively small. If the wave energy can be collected on a large scale efficiently and stably, its energy can be applied to seawater desalination equipment, and at the same time, avoiding the contact of various equipments with high-pressure seawater, simplifying the seawater desalination step and reducing the desalination cost, it is expected to promote the application of wave energy better. Desalination technology.

The New Ship Energy Efficiency Design Index (EEDI) developed by the International Maritime Organization is an indicator used to assess the carbon dioxide efficiency of a ship, is the ratio of social benefits to carbon dioxide emissions generated per unit of the ship. After the implementation of EEDI, new ships must comply with EEDI standards and promote the development of green ship design; and the application of wave energy, such as renewable energy, to ship power generation can effectively reduce ship carbon emissions. Based on the above analysis, the application trends of wave energy generation technology on ships are as follows: In the initial stage of ship design, fully consider the use of wave energy. Wave power generation is used as a ship auxiliary and domestic electricity. Wave energy can be combined with other new energy sources. Wave energy self-propelled power station.

Desalination and comprehensive utilization of seawater are important directions for the development of wave energy. Desalination and wave energy supply are important for solving the energy supply in remote islands and coastal countries. At present, human demand for fresh water is increasing, and desalination can greatly alleviate the pressure on people's demand for fresh water. Especially for remote islands, wave energy plants can provide electricity supply and fresh water supply, which can promote the development and utilization of islands.

The use of ocean wave energy for comprehensive research such as aquaculture and hydrogen production is a new way to utilize ocean energy. Marine aquaculture is an important economic activity of the country. It is of great significance to use wave energy to achieve sea state monitoring, energy supply and improvement of farming conditions. The use of wave energy to produce hydrogen can indirectly achieve the storage of wave energy, and can provide raw materials for power generation devices such as fuel cells.

Desalination and comprehensive utilization of seawater are important directions for the development of wave energy. Desalination and wave energy supply are 
important for solving the energy supply in remote islands and coastal countries. At present, human demand for fresh water is increasing, and desalination can greatly alleviate the pressure on people's demand for fresh water. Especially for remote islands, wave energy plants can provide electricity supply and fresh water supply, which can promote the development and utilization of islands.

The use of ocean wave energy for comprehensive research such as aquaculture and hydrogen production is a new way to utilize ocean energy. Marine aquaculture is an important economic activity of the country. It is of great significance to use wave energy to achieve sea state monitoring, energy supply and improvement of farming conditions. The use of wave energy to produce hydrogen can indirectly achieve the storage of wave energy, and can provide raw materials for power generation devices such as fuel cells.

\section{References}

1. MattFolley, BaltasarPeateSuarez, TrevorWhittaker. Anautonomouswave-powereddesalination system [J].Desalination, 2008,220: 412-421.

2. L. Fernández Prieto, (2018) Wave energy to power a desalination plant in the north of Gran Canaria Island: Wave resource, socioeconomic and environmental assessment. Science Direct:546-551.

3. Ban peng, (2018) Wave energy development overview. Inner Mongolia science technology \& economy: 51-51.

4. Duan chunming, (2017) Research on power system of wave energy and tidal energy power generation. Distributed energy: 31-37.

5. Liang Li, (2018) Investigation on long-term extreme response of an integrated offshore renewable energy device with a modified environmental contour method. Science Direct: 33-42.

6. Elie AL Shami, (2018) A parameter study and optimization of two body wave energy converters. Science Direct: 1-13.

7. Li Wang, Dong-Jing Lee, Wei-Jen Lee, et al. Analysis of a novel autonomous marine hybrid power generation/ energy storage system with a high-voltage direct current link[J].Journal of Power Sources,2008,185(2):1284-1292.

8. Wu Bijun, You Yago, Ma Yujiu, et al. Automatic Control System for Independent and Stable Generation of Wave Energy [J]. Automation of Electric Power Systems, 2007,24 (31): 75-79.

9. YU Zhi. The development of ocean wave power generating techniques[J]. The Ocean Engineering. 1993, 11(1): 86-93

10. Wang Dongsheng, Li Shihua, Zhou Xingpeng. Evaluation method and application of raw water quality based on PSO-RBF neural network model [J]. Journal of Southeast University: Natural Science Edition, 2011, 41 (5): 1019-1023

11. Alain Clément, Pat Mccullen, António falco. Wave energy in Europe: current status and perpectives[J].
Renewable \& Sustainable Energy Reviews, 2002(6): 405-431. 